\title{
PRODUCTIVITY IMPROVEMENT IN FLUX ASSISTED TIG WELDING
}

\author{
Santhana Babu A.V. ${ }^{1}$, Giridharan P.K. ${ }^{2}$ \\ ${ }^{1}$ Scientist, Satish Dhawan Space Centre, SHAR, ISRO, Department of Space, India \\ ${ }^{2}$ Shri Ranganathar Institute of Engineering and Technology, Athipalayam, Coimbatore, India. \\ Email: 1 santhanababu.av@shar.gov.in
}

\section{Abstract}

TIG welding is most common welding process to weld highly reactive materials like aluminum alloys, magnesium alloys, stainless steels etc. However the process is not cost competitive due to low penetration potential. Generally work pieces thicker than $3 \mathrm{~mm}$ cannot be welded autogenously by TIG welding. Hence after joint preparation, multipass welding is done to weld plates of higher thickness. To improve penetration capability of TIG process, flux assisted TIG welding has been developed and this has drawn the attention of researchers in the recent past. This review attempts to present the current understanding in the development of flux assisted TIG welding. In this paper ATIG (Activated Flux TIG) and recently developed FBTIG (Flux Bounded TIG) processes, weld pool convection, the mechanism of penetration, fluxes for welding different alloys are discussed. Aluminum alloy is the preferred material in aerospace technology, due to its high strength to weight ratio. The flux assisted TIG welding of aluminum alloys is presented in detail due to its aerospace application. The effects of different modes of current namely, alternating current (AC), direct current electrode negative (DCEN) and direct current electrode positive (DCEP) on aluminum alloy welds are also presented. The aim of this paper is to highlight the recent progress in flux assisted TIG welding and provide a basis for follow-on research.

Key words: Flux Assisted TIG, Activated Flux TIG, ATIG, FBTIG, Penetration Improvement

\section{INTRODUCTION}

Tungsten inert gas welding (TIG) is the arc based process between a tungsten electrode and work piece. Because of its simplicity, good weld appearance, low initial cost and feasibility to join bigger structures, this process is commonly used to join reactive materials like stainless steel, magnesium alloy, aluminum alloy etc. However the disadvantage of this process is relatively low penetration capability and hence it is not considered as cost competitive. It is well understood from Fig 1 that TIG (GTAW) has the least penetration capability when compared with other processes. Generally TIG welding process can be used to weld material thickness up to $3 \mathrm{~mm}$ in single pass. Hence higher thickness plates cannot be welded autogenously. Higher thickness materials are joined by multipass welding which needs joint preparations and filler additions. To improve the weld penetration in titanium alloys, in 1960s, Paton Electric Welding Institute has developed a new flux assisted TIG welding process called ATIG (Activated Flux TIG) process in which a thin layer of activating flux is applied on the surface of the material prior to welding. However the composition of the flux is not published. Since then ATIG has attracted the attention of researchers to investigate the mechanism of deep penetration and development of flux for different materials.

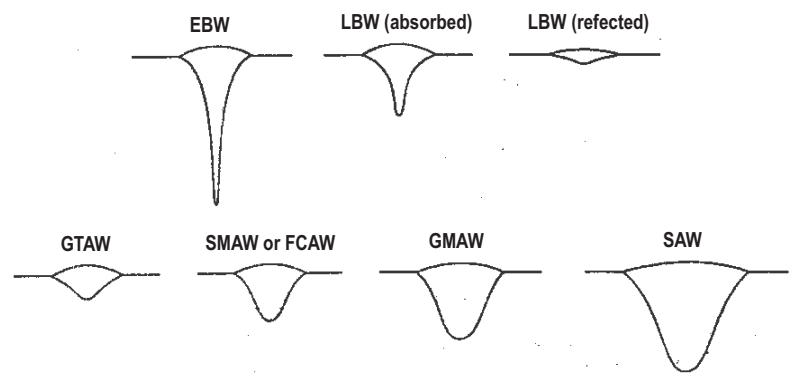

EBW-Electron Beam Welding

LBW-Laser Beam Welding

SAW-Submerged Arc Welding

GMAW-Gas Metal Arc Welding

SMAW-Shielded Metal Arc Welding

FCAW-Flux Cored Arc Welding

GTAW-Gas Tungsten Arc Welding

Fig 1. Comparison of penetration depth in various welding processes (1)

\section{FLUX ASSISTED TIG WELDING PROCESS}

The ATIG welding process is schematically shown in Fig 2. The flux powder is mixed in acetone 
and applied on the material surface by using a brush. On drying a thin layer of flux coat is formed on the work surface.

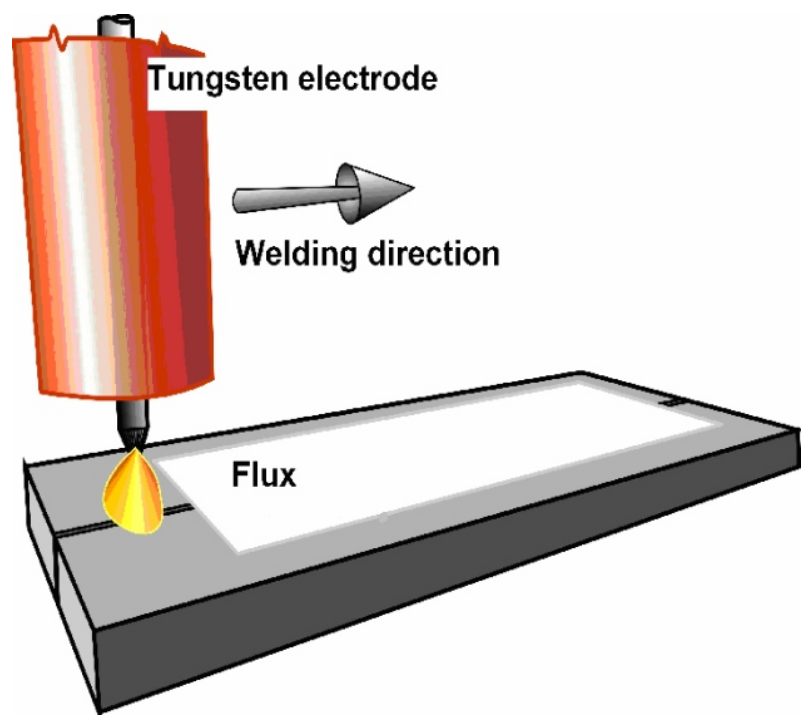

Fig 2. Scheme of ATIG welding

For cosmetic and deep welds in aluminum alloys, later French researchers Sire and Marya (2) have modified the process by applying two symmetric flux coatings closer to the weld joint by maintaining a small clearance between them as shown in fig 3. This process is named as FBTIG (Flux Bounded TIG).

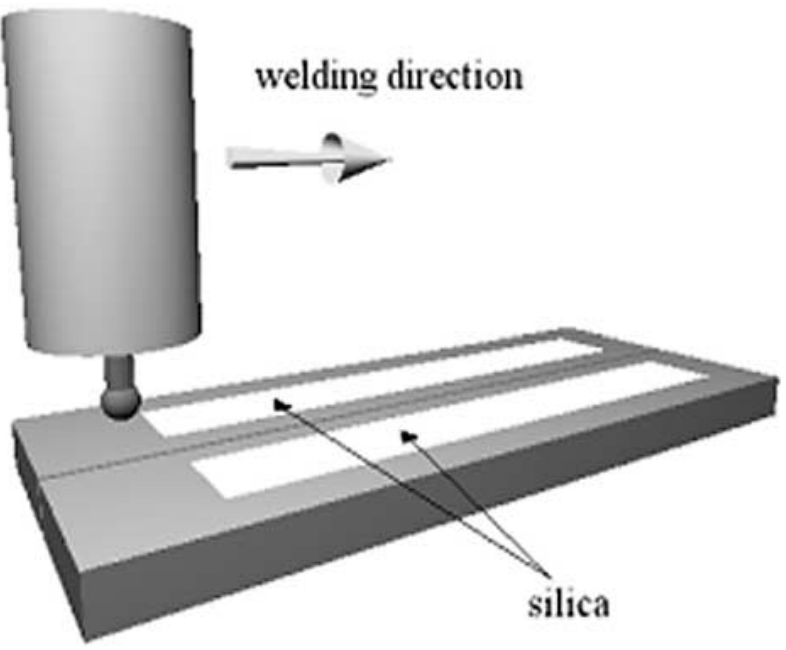

Fig 3. Scheme of FBTIG welding

\section{MECHANISMS OF DEEPER PENETRATION IN FLUX ASSISTED TIG WELDING}

The research on the mechanism that the activating flux improves weld penetration is important for the development of new fluxes. After extensive research, the following two mechanisms are widely accepted by most of the researchers for deeper penetration in both ATIG and FBTIG processes.

\section{A. Constriction of the electric arc}

The current path in the case of TIG welding process without flux expands widely over the whole weld pool surface area and hence the penetration is shallow and wide. However in the ATIG process (3), the flux particles at the central zone are melted and the unmelted flux particles in the surrounding outer zone offer resistance to the current flow. As a result, the current path is constricted at the centre. In FBTIG process (2), the absence of flux in central zone makes it more conducting than the outer regions and arc constriction occurs. The constricted arc delivers concentrated heat flux at the central zone which gives deeper penetration as shown in Fig 4.
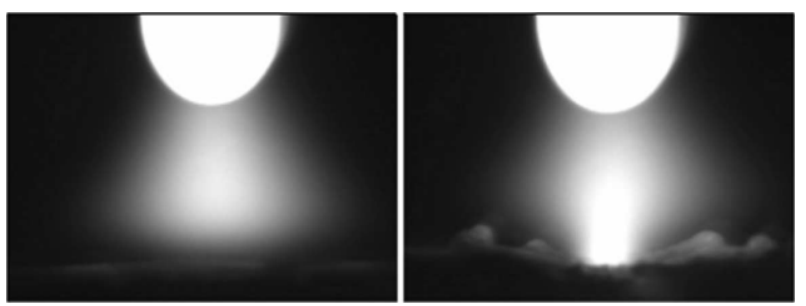

Fig 4. Unconstricted arc in the conventional $\mathrm{TIG}$ process in left and constricted arc in FBTIG process in right.

Further the resistance offered by the flux coating to the flow of current deflects the arc and hence arc root is lagging behind the electrode as shown in Fig 5 .
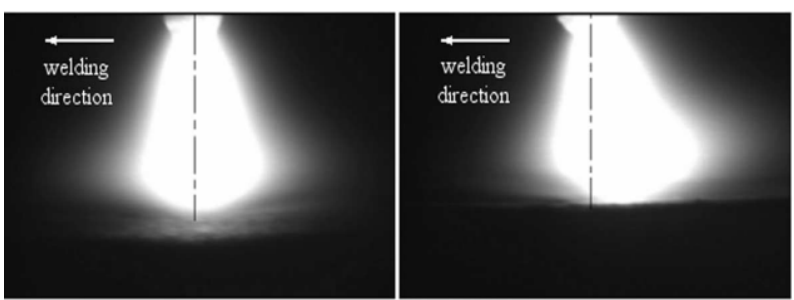

Fig 5. Undeflected arc in the conventional TIG process in left and deflected arc in ATIG process in right.

\section{B. Reversed Marangoni Convection}

Convection of liquid metal in weld pool is governed by buoyancy force, Lorentz. (electro 
magnetic) force, Marangoni (surface tension) convection and shear stress induced by plasma jet as shown in Figure 6 (3).

\section{Buoyancy Force}

This force generates due to the density difference (based on temperature variation) of liquid metal within the weld pool. Since the heat source is located above the center of the pool surface, the liquid metal is warmer (hence less dense) at pool centre ' $a$ ' and cooler (hence more dense) at pool boundary ' $b$ '. Consequently, the liquid metal falls along the pool boundary and rises along the pool axis, as shown in Figure 6.

\section{Lorentz Force}

The current field, together with the magnetic field it induces, in the process causes a downward and inward Lorentz force, as shown in figure 6. As such, the liquid metal is pushed downward along the pool axis and rises along the pool boundary.

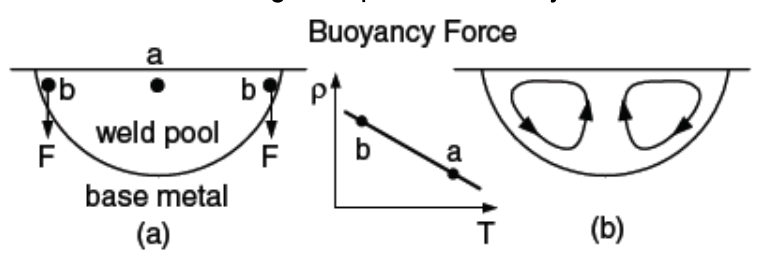

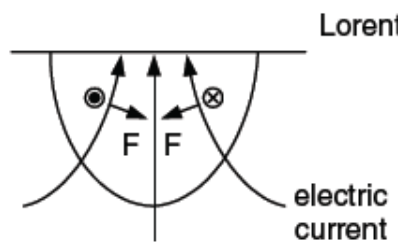

(c)

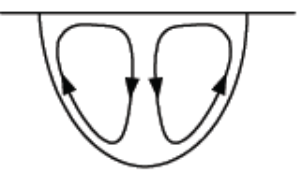

(d)

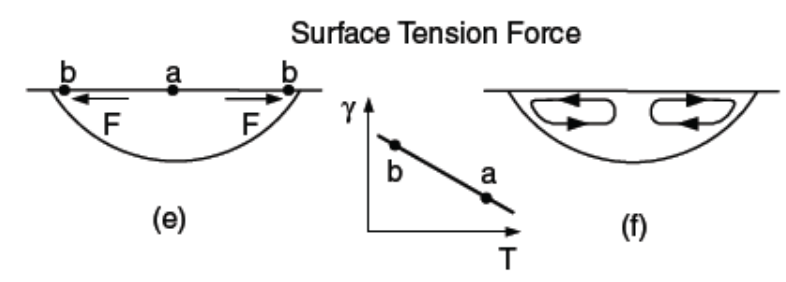

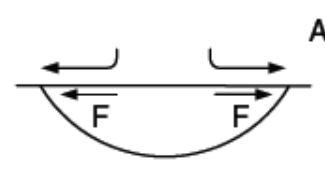

(g)
Arc Shear Stress

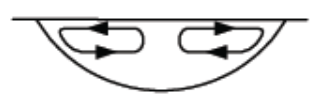

(h)
Fig 6. Driving Forces for Weld Pool Convection: $(a, b)$ buoyancy force; $(c, d)$ Lorentz force; $(e, f)$ shear stress caused by surface tension gradient (Marangoni convection); $(g, h)$ shear stress caused by arc plasma (3).

\section{E. Marangoni convection}

This convection arises due to shear stress induced by surface tension gradient. In the absence of a surface-active agent, the surface tension $(\mathrm{g})$ of the liquid metal decreases with increasing temperature $(T)$, namely, $\delta \mathrm{g} / \delta T<0$. As shown in Figure 6 , the warmer liquid metal with a lower surface tension at point ' $a$ ' is pulled outward by the cooler liquid metal with a higher surface tension at point ' $b$ '. This causes the liquid metal to flow from the center of the pool surface to the edge and return below the pool surface, as shown in Figure 6. Surface tension driven convection is also called thermo capillary convection or Marangoni convection.

\section{F. Shear Stress Induced by Plasma Jet}

The plasma moving outward at high speeds along a pool surface can exert an outward shear stress at the pool surface, as shown in Figure 6. This shear stress causes the liquid metal to flow from the center of the pool surface to the pool edge and return below the pool surface.

\section{G. Reversed Marangoni convection:}

From the Figure 6 , it is evident that out of the four forces mentioned here, Lorentz force alone is aiding deeper penetration of weld.

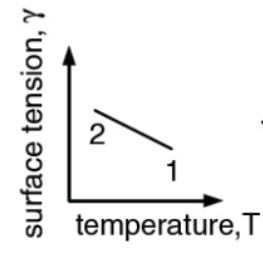

(a)

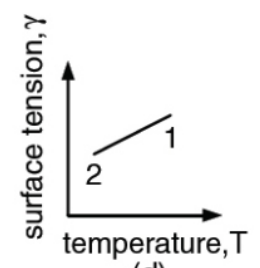

(d)

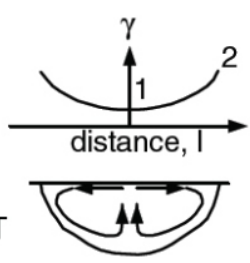

(b)

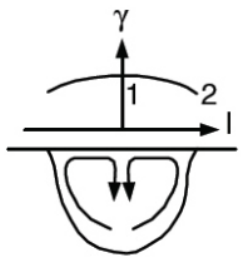

(e)

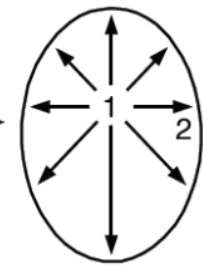

(c) $\uparrow$ welding
Fig 7. Marangoni flow in weld pool (a-c) without surface activation elements (d-e) with surface activation elements (3).

However by adding surface active agents (4-7), the surface tension gradient can be made positive as shown in Fig 7. (3). Due to this change, at weld pool surface, convective flow happens from outer edge 
towards the centre of the pool. This is called reversed Marangoni convection which aids deeper weld penetration (4).

\section{DEVELOPMENTS IN FLUX ASSISTED TIG WELDING IN DIFFERENT MATERIALS}

Literature survey indicates published papers are very few in respect of materials mild steel/carbon steel (8-13) and titanium alloy (14). However researchers have given more importance to the materials stainless steel (15-27), magnesium alloy (28-35) and aluminum alloy (36-47). Hence development in flux assisted TIG welding is discussed in detail for these three materials. It is observed different material needs different type of flux.

\section{A. Stainless Steels}

In stainless steel ATIG process, using a mixture containing $70 \%$ helium in argon, as shielding gas is found to give deeper penetration [15]. It is found ATIG weld penetration is not varying due to the chemical composition differences between heats of material being welded [16]. While comparing the effect of various fluxes on SS 304 weld, it has been found $\mathrm{SiO}_{2}, \mathrm{TiO}_{2}, \mathrm{Fe}_{2} \mathrm{O}_{3}$ and $\mathrm{AlF}_{3}$ are giving encouraging results $[17,18]$ as shown in Figure 8 . Out of these four fluxes, $\mathrm{SiO}_{2}$ is the most recommended one by the researchers $[19,20,21,22,25]$. The smaller the flux particle size of the order 0.8 microns, the deeper the penetration is [19]. This is because smaller particles decompose easily during the process. The optimal thickness of the flux coating is found to be between 40 and 70 microns depending upon the welding current [21]. Motorised welding is recommended [23] in using ATIG process for welding materials above $5 \mathrm{~mm}$ thick. ATIG weldment exhibits better mechanical properties (including strength, ductility and hardness) than those of TIG welding without flux [25].

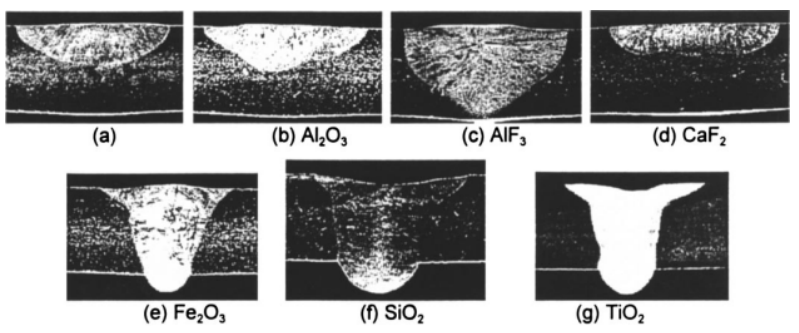

Fig 8. Cross section of weld beads in $5 \mathrm{~mm}$ thick SS 304 plates for (a) conventional TIG and (b-g) ATIG welding [17]
Apart from improving penetration depth, in austenitic stainless steel weld, addition of up to $10 \%$ nitrogen with argon shielding gas [26] has decreased angular distortion due to weld, reduced retained delta ferrite content, improved mechanical properties such as tensile strength and hardness and reduced hot cracking susceptibility. Further investigation with the addition of up to $5 \%$ hydrogen in argon shielding is also found to give similar results [27].

\section{B. Magnesium Alloys:}

Though magnesium alloy has low density, it is not being used much in aerospace applications partly because of its low formability. For increasing weld penetration in magnesium alloys, chlorides are tested (28). Among the various chlorides $\mathrm{LiCl}_{2}, \mathrm{CaCl}_{2}$, $\mathrm{CdCl}_{2}, \mathrm{PbCl}_{2}$ and $\mathrm{CeCl}_{2}$ studied, cadmium chloride has given best result. It has increased the penetration depth by more than $100 \%$ in welding of magnesium alloys $A Z 21$ and $A Z 31 B[28,29]$ as shown in fig 9. Further investigations [30] have given good results in AZ31B alloy weld by using a mixture of $40 \% \mathrm{MnCl}_{2}$ and $60 \%$ $\mathrm{ZnO}$ also as flux. To develop oxide fluxes LM Liu et al [31] has investigated the effect of using $\mathrm{MgO}, \mathrm{CaO}$, $\mathrm{TiO}_{2}, \mathrm{MnO}_{2}$ and $\mathrm{Cr}_{2} \mathrm{O}_{3}$ on magnesium alloy welds and observed $\mathrm{MgO}$ and $\mathrm{MnO}_{2}$ are giving better results than the rest as shown in Fig 10.

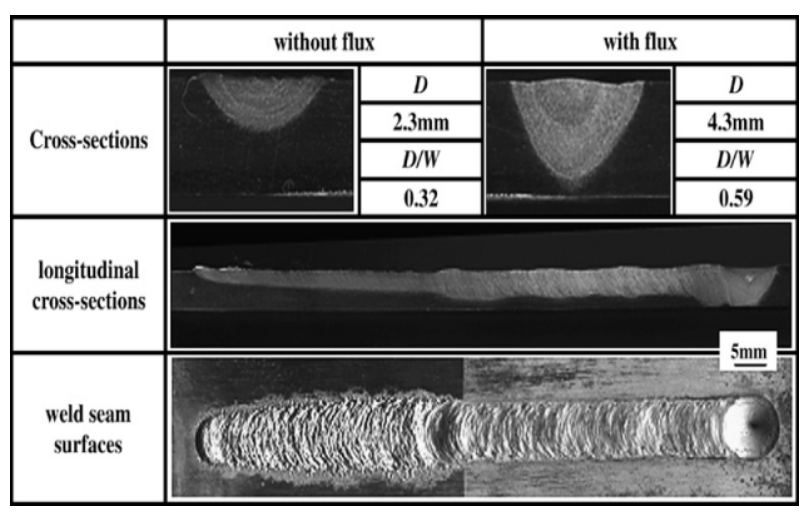

Fig 9. Comparison of penetration depth in $5 \mathrm{~mm}$ thick magnesium alloy $\mathrm{AZ31B}$ with flux $\mathrm{CdCl}_{2}$ [29]

However $\mathrm{TiO}_{2}$ and $\mathrm{Cr}_{2} \mathrm{O}_{3}$ are also found as good candidates when compared with $\mathrm{SiO}_{2}$ in improving weld penetration [35]. $\mathrm{SiO}_{2}$ has created a cavity in the weld bead because of loss of base metal probably due to the reaction of flux with the base metal. 


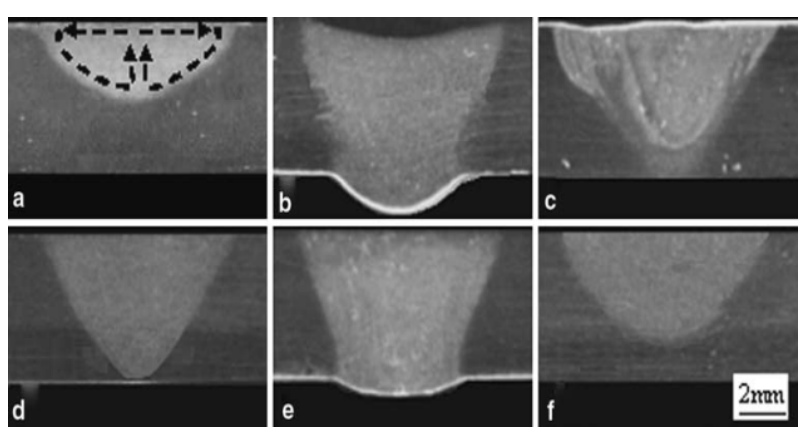

Fig 10. Effect of activating fluxes on AZ31B alloy weld morphology: (a) without flux, (b) MgO flux, (c) $\mathrm{CaO}$ flux, (d) $\mathrm{TiO}_{2}$ flux, (e) $\mathrm{MnO}_{2}$ flux, and (f) $\mathrm{Cr}_{2} \mathrm{O}_{3}$ flux [31].

Reduction in tensile strength is reported in magnesium alloy ATIG welds that use either chlorides or oxides as flux when compared with welds without flux $[29,30]$ which is undesirable. It is found flux coated wire can also improve penetration in magnesium alloy welds [30, 32]. Using Te powder and $\mathrm{ZnF}_{2}$ refines grain structure in weld apart from improving penetration [33, 34].

\section{Aluminum Alloys:}

Silica $\left(\mathrm{SiO}_{2}\right)$ is the recommended flux by most of the researchers for aluminum alloy weld [36, 37, 39, 42, 43, 46]. Improved depth / width ratio is reported $[36,37]$ by using silica flux in FBTIG welding of alloy 5086. When flux gap was $4 \mathrm{~mm}$, the ratio reached 0.52 [41]. The multi component activating flux AF305 (for which composition is not disclosed) developed by

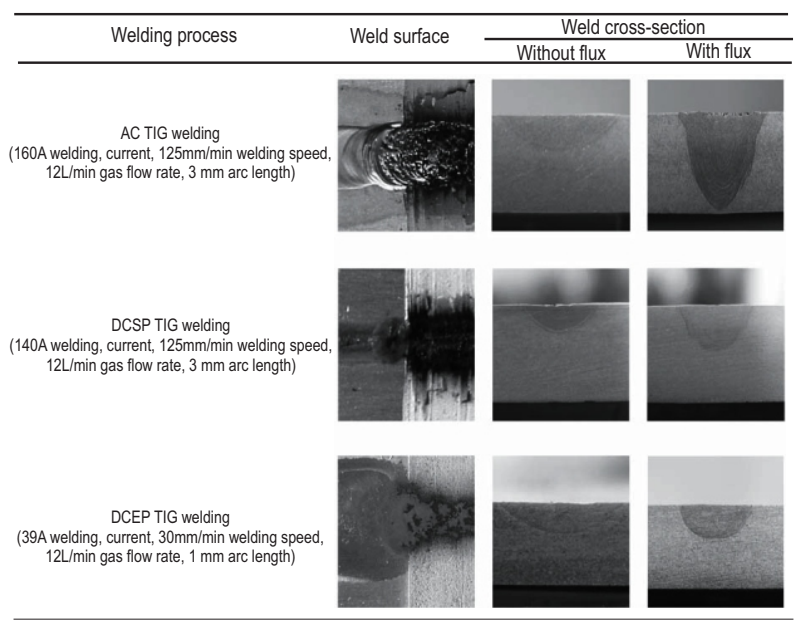

Fig 11. Effects of Polarity on weld shape of ATIG welding of alloy AA 3003 with Flux AF305 [44].
Huang Yong et al [44] is used to weld alloy 3003 to study the effect of current polarities namely Alternating Current (AC), direct current electrode positive (DCEP) and direct current electrode negative (DCEN) which is also called as direct current straight polarity (DCSP) on weld penetration. Fig 11 shows the results.

The duration of $\mathrm{AC}$ TIG welding can be sub divided into DCEP duration and DCSP duration. Deep penetration is associated with DCEN polarity and cathode cleaning action is associated with DCEP as shown in Fig 12.

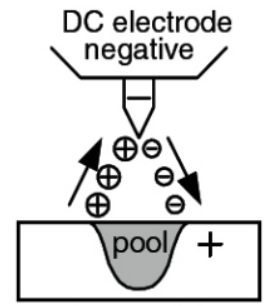

deep weld, no surface cleaning (a)

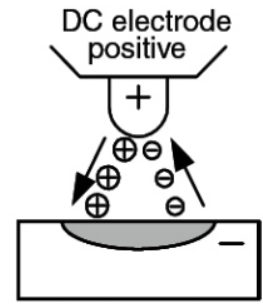

shallow weld, surface cleaning

(b)

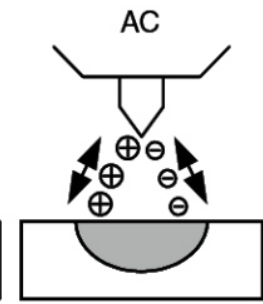

intermediate

(c)
Fig 12. Comparison of weld penetration between DCEN, DCEP and AC polarities (3)

Since AC ATIG welding consists of both DCEP and DCSP, a clean weld with penetration (over two times more than that of conventional TIG welding) could be obtained. In DCSP ATIG welding shown in Fig 11, weld penetration is improved but, an oxide film still exists on the weld surface in the region without flux because, cathode cleaning action does not work.

In the region with flux, a black flux layer covers the entire weld surface. In DCEP ATIG welding, the weld surface without flux presents metal luster. In the region with flux, black slag distribution is observed on the surface. However the improvement in weld penetration is very little. Hence for ATIG welding AC polarity is considered as best among the three options. It is stated the flux AF 305 (for which the chemical composition is not disclosed) is having low current resistivity, melting temperature and boiling temperature when compared with $\mathrm{SiO}_{2}$ and hence lesser arc constriction is expected from the former than later. However fig 13 indicates deeper penetration in using flux AF 305. Slag distribution on weld pool surface is considered as the reason for this. But this phenomenon is not discussed in any other literature. As a further improvement from FBTIG, a layer of low melting 


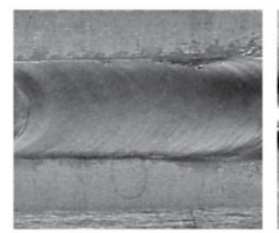

TIG

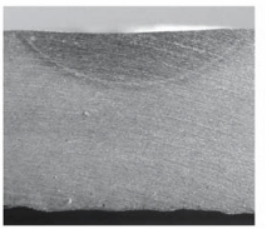

TIG

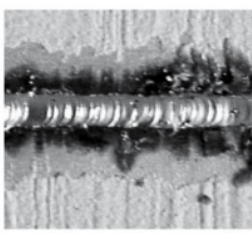

$\mathrm{SiO}_{2}$

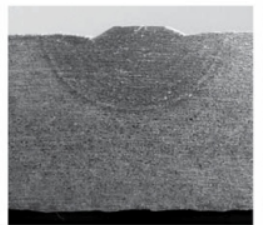

$\mathrm{SiO}_{2}$

(b)

(a) Weld Surface (b) Weld Cross-Section.
Fig 13. Comparison of weld penetration between conventional TIG, FBTIG with flux SiO2 and ATIG with flux AF 305 [44]

temperature and low resistance activating flux was coated in the center surface area of aluminum alloy plate and two layers of high melting temperature and high resistance activating flux was coated alongside the former area. This method is named as Flux Zoned TIG (FZTIG) $[45,47]$ which has not only increased weld penetration, but also gave good weld surface appearance, fine weld microstructure and improved mechanical properties.

\section{CONCLUSION AND FUTURE OUTLOOK}

The demonstrated advantages in flux assisted TIG process have now attracted the researchers to look for similar improvements in using flux assistance in other processes like Laser Welding [48], Electron Beam Welding [49, 50], Gas Metal Arc Welding [51], Arc Stud Welding [52] etc. However, the investigations done so far are focused in the following areas: (a) Improvement in penetration depth in ATIG/FBTIG (b) Effect of shielding gas on penetration depth (c) Effect of variation of flux on penetration depth (d) Effect of current polarity AC/DCEN/ DCEP on weld quality and penetration depth. Though good amount of findings are published in the literature in the flux assisted TIG process in stainless steel, magnesium alloys and aluminum alloys, the following areas are still untouched and not reported in publications: (a) Improvement in mechanical properties, (b) Corrosion resistance (c) Efforts to optimize, control and regulate the welding parameters to improve the weld quality (d) Welding dissimilar materials (e) Modeling and simulation (f) Establishing relationship between mechanical properties and welding process parameters. Hence this review paper helps identifying the area in which further research can follow.

\section{REFERENCES}

[1] Robert W Messler Jr, 1999, "Principles of Welding", John Wiley \& Sons, Inc., New York, USA.

[2] Marya S., 2006, "Overview of Innovative Developments in Science and Technology of Welding", International Journal of Mechanical and Materials Engineering (IJMME), Volume 1, No1, pp 1-10.

[3] Sindo Kou, 2003, "Welding Metallurgy", Second Edition, John Wiley \& Sons, Inc., Hoboken, New Jersey.

[4] CR. Heiple and JR. Roper, 1982, "Mechanism for Minor Element Effect on GTA Fusion Zone Geometry", Welding Journal 61(4), pp 97-102.

[5] Lucas W and Howse D, 1996, "Activating FluxIncreasing the performance and Productivity of the TIG and Plasma Processes", Welding and Metal Fabrication 64[1], pp 11-17.

[6] Aidun D.K. and Martin S.A., 1997, "Effect of Sulphur and Oxygen on Weld Penetration of High-Purity Austenitic Stainless Steels", Journal of Materials Engineering and Performance, Volume 6(4), pp 496-502.

[7] Shanping Lu, Hidetoshi Fujii and Kiyoshi Nogi, 2004, "Marangoni Convection in Weld Pool in CO2-Ar Shielded Gas Thermal Arc Welding", Metallurgical and Materials Transactions A, Volume 35A, pp 2861-2867.

[8] Fan Ding, Gu Yu Fen, Lin Yan, Shi Yu and Zhang Ruihua, 2000-03, "Experimental Study of A-TIG Procedure for Mild Steel Welding", Journal of Gansu University of Technology.

[9] Zhang Ruihua and Fan Ding, 2001-04, "Development of Efficient Activating Flux for TIG Welding of Low-Carbon Steel", Journal of Gansu University of Technology.

[10] Zhang Ruihua and Fan Ding, 2001-05, "Development of an Activation Flux for the GTAW of Low Carbon Steel", Development and Application of Materials.

[11] Fan Ding, Gu Yufen, Shi Yu and Zhang Ruihua, 2002-02, "Experimental Study of A-TIG Procedure of Carbon Steel", Welding \& Joining.

[12] Zhang Rui hua and Fan Ding, 2003-01, "Study of Weldability of Activating Flux for A-TIG Welding of Mild Steel", Journal of Gansu University of Technology. 
[13] Zhang Rui-hua and Fan Ding, 2003-01, "Weldability of Activating Flux in A-TIG Welding for Mild Steel", Transactions of The China Welding Institution.

[14] Huang Yong, Fan Ding and Zhang Han, 2006-10, "Effect of Surface Activating Flux on Weld Penetration of A-TIG Welding for Titanium Alloy", Rare Metal Materials and Engineering.

[15] Anderson PJC and Wiktorowicz R., 1996, "Improving Productivity with ATIG Welding", Welding and Metal Fabrication, 64 (3), pp 108-109

[16] Paskell T, Lundin C and Castner H, 1997, "GTAW Flux Increases Weld Joint Penetration", Welding Journal, 76(4), pp 57-62.

[17] Paulo J. Modenesi, Eustaquio R. Apolinario and laci M. Pereira, 2000, "TIG Welding With Single-Component Fluxes", Journal of Materials Processing Technology 99, pp 260-265.

[18] Tanaka M., Shimizu T., Tearsaki H., Ushio M., Koshi-ishi F. and Yang C.L., 2000, "Effect of Activating Flux on Arc Phenomena in Gas Tungsten Arc Welding", Science and Technology of Welding and Joining, Vol 5, No 6, pp 397-402.

[19] Shanping Lu, Hidetoshi Fujii, Hiroyuki Sugiyama and Kiyoshi Nogi, 2003, "Mechanism and Optimisation of Oxide Fluxes for Deep Penetration in Gas Tungsten Arc Welding", Metallurgical and Materials Transactions A, Volume 34A, pp 1901-1907.

[20] Chunli YANG, Sanbao LIN, Fengyao LIU, Lin WU and Qingtao ZHANG, 2003, "Research on the Mechanism of Penetration Increase by Flux in A-TIG Welding", Journal of Material Science and Technology, Vol 19, Supplement 1, pp 225-227

[21] Ruckert G., Huneau B. and Marya S., 2007, "Optimizing the Design of Silica Coating for Productivity Gains During the TIG Welding of 304L Stainless Steel", Materials and Design 28, pp 2387-2393.

[22] Qing-ming LI, WANG Xin-hong, ZOU Zeng-da, WU Jun, 2007, "Effect of Activating Flux on Arc Shape and Arc Voltage in Tungsten Inert Gas Welding", Trans Nonferrous Met Soc, China, pp 486-490.

[23] Sandor T. and Janos Dobranszky, 2007, "The Experiences of Activated Tungsten Inert Gas (ATIG) Welding Applied on 1.4301 Type Stainless Steel Plates", Materials Science Forum, Volumes 537-538, pp 63-70

[24] Tamas Sandor, 2008, "ATIG Welding of Duplex Steel", Materials Science Forum, Volume 589, pp 49-54.

[25] Shyu S.W., Huang HY, Tseng KH and Chou CP, 2008, "Study of the Performance of Stainless Steel A-TIG Welds", Journal of Material Engineering and Performance, Volume 17(2), pp 193-201.
[26] Her-Yueh Huang, 2009, "Effects of Shielding Gas Composition and Activating Flux on GTAW Weldments", Materials and Design 30, pp 2404-2409.

[27] Her-Yueh Huang, 2010, "Argon-Hydrogen Shielding Gas Mixtures for Activating Flux Assisted Gas Tungsten Arc Welding", Metallurgical and Materials Transactions A, Volume 41A, pp 2829-2835.

[28] Marya M. and Edwards GR., 2002, "Chloride Contributions in Flux-Assisted GTA Welding of Magnesium Alloys", Welding Journal, pp 291S-298S

[29] Zhang Z.D., Liu L.M., Shen Y. and Wang L., 2008, "Mechanical Properties and Microstructures of a Magnesium Alloy gas Tungsten Arc Welded with a Cadmium Chloride Flux", Materials Characterization, 59, pp 40-46.

[30] Liu L.M., Cai D.H. and Zhang Z.D., 2007, "Gas Tungsten Arc Welding of Magnesium Alloy Using Activated Flux-Coated Wire", Scripta Materialia 57, pp 695-698.

[31] Liu L.M, Zhang ZD, Song G. and Wang L., 2007, "Mechanism and Microstructure of Oxide Fluxes for Gas Tungsten Arc Welding of Magnesium Alloy", Metallurgical and Materials Transactions A, Volume 38A, pp 649-658.

[32] Liu Liming, Cai Donghong, Zhang Zhaodong and Zhu Meili, 2007-04, "A-TIG Welding of Magnesium Alloy with Activating Welding Wire", Transactions of China Welding Institution.

[33] Huang Yong, Fan Ding, Yang Peng and Lin Tao, 2007-06"Effects of Activating Fluxes on AC A-TIG Weld Penetration of Magnesium Alloy", Transactions of the China Welding Institution.

[34] Huang Yong, Fan Ding, Lin Tao and Shao Feng, 2007-10, "Effects of Activating Fluxes on DCSP A-TIG Weld Penetration of Magnesium Alloy", Transactions of the China Welding Institution.

[35] Zhaodong Zhang, Liming Liu, Hao Sun and Lai Wang, 2008, "AC TIG Welding with Single Component Oxide Activating Flux for AZ31B Magnesium Alloys", Journal of Material Science, 43 pp 1382-1388.

[36] Stephane Sire and Surendar Marya, 2002, "On the Selective Silica Application to Improve Welding Performance of the Tungsten Arc Process for a Plain Carbon Steel and for Aluminum", C.R.Mecanique 330, pp 83-89.

[37] Sire S. and Surendar M., 2002, "On the Development of a New Flux Bounded TIG Process (FBTIG) to Enhance Weld Penetrations in Aluminum 5086", International Journal of Forming Processes, Volume 5/1, pp 39-51. 
[38] Fan Ding, Huang Yong, Zhang Ruihua and MA Baorong, 2003-02, "Application of the Uniform Design Method in Developing A-TIG Activating Fluxes for Aluminum Alloy", Journal of Gansu University of Technology.

[39] Fan Ding and Huang Yong, 2003-03, "Effects of Activating Fluxes and Welding Parameters on Penetration in AC A-TIG Welding for Aluminum Alloy", Journal of Gansu University of Technology.

[40] Huang Yong and Fan Ding 2003-04, "Mechanism of Weld Penetration Increase of AC A-TIG Welding for Aluminum Alloy", Welding \& Joining.

[41] Huang Yong, Fan Ding and Fan Qinghua, 2004-03, "Experimental Study on FBTIG Welding for Aluminum Alloy", Welding \& Joining.

[42] Huang Youg, Fan Ding and Fan Qing-hua, 2004-05, "Effect of Surface Activating Flux on Welding Penetration of A-TIG Welding with DCSP Mode of Aluminum Alloy" Transactions of The China Welding Institution.

[43] Huang Yong, Fan Ding and Fan Qing-hua, 2005-04, "Effect of Surface Activating Flux on Welding Penetration of Aluminum Alloy A-TIG Welding with DCRP Mode" Welding Technology.

[44] Huang Yong, Fan Ding and Fan Qinghua, 2007, "Study of Mechanism of Activating Flux Increase Weld Penetration of AC A TIG Welding for Aluminum Alloy" Front Mechanical Engineering China, 2(4), pp 442-447 [Translated from Chinese Journal of Mechanical Engineering, 2006, 42(5), pp 45-49]

[45] Huang Yong, Shao Feng, 2007-05, Fan Ding and Lin Tao, "Flux Zoned Activating TIG Welding of Aluminum Alloys" Welding \& Joining.
[46] Huang Yong and Fan Ding, 2008-01, "Mechanism of Weld Penetration Increased by $\mathrm{SiO} 2$ in $\mathrm{AC}$ A-TIG Welding for Aluminum Alloy", Transactions of the China Welding Institution.

[47] Huang Yong, Shao Feng and Fan Ding, 2009-03, "Analysis of Process Factors of AC FZ-TIG Welding for Aluminum Alloy", Welding Technology.

[48] Kuo M., Sun Z. and Pan D., 2001, "Laser Welding with Activating Flux", Science and Technology of Welding and Joining, Volume 6, No1, pp 17-22.

[49] Fan Ding, Fan Qing-hua and Huang Yong, 2005-06, "Effect of Activating Fluxes on Electron Beam Welding of Aluminum Alloy, Journal of Gansu University of Technology.

[50] Zhang Ruihua, Fan Ding and Katayama Seiji, 2006, "Electron Beam Welding with Activating Flux", Transactions of JWRI, Volume 35, No 2, pp 19-22.

[51] Her-Yueh Huang, 2010, "Effects of Activating Flux on the Welded Joint Characteristics in Gas Metal Arc Welding", Materials and Design 31, pp 2488-2495.

[52] Samardzic I., Bajic D. and Klaric S., 2010, "Influence of the Activating Flux on Weld Joint Properties at Arc Stud Welding Process", Metalurgija 49, pp 325-329.

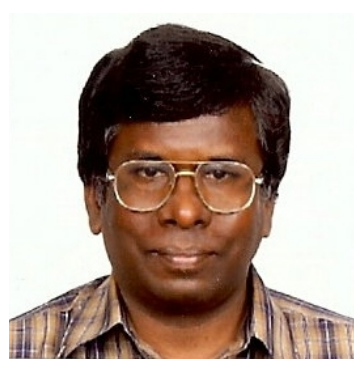

The author is a Scientist in Indian Space Research Organization, India and doing research in the area of "Characterization of Flux Assisted TIG Welding" in Sathyabama University, Chennai, India. 